\title{
A PILOT STUDY ON SUN PROTECTION FACTOR OF PLANT EXTRACTS: AN OBSERVATIONAL STUDY
}

\author{
PRIYANKA S ${ }^{1}$, MARY SHOBHA RANI INALA ${ }^{2}$, NANDINI HS ${ }^{2}$, KUTTY AVM ${ }^{2}$, KIRANMAYEE ${ }^{2 *}$
}

${ }^{1}$ Department of Microbiology and Cell Biology, Indian Institute of Science, Bengaluru, Karnataka, India. ${ }^{2}$ Department of Cell Biology and Human Genetics, Sri Devaraj Urs Academy of Higher Education and Research, Tamaka, Kolar - 563 103, Karnataka, India. Email: kiranmayeep@sduu.ac.in

Received: 15 November 2017, Revised and Accepted: 15 December 2017

ABSTRACT

Objective: The aim of the present work is to investigate the presence of ultraviolet (UV) light absorption capacity of the selected plant extracts. Chemical-based sunscreens provide protection against the sun's rays, in particular, UV radiation. Sometimes, exposure to these chemicals leads to allergies to the skin. The best way to protect skin from chemical and photoallergies is to use plant-based creams and lotions.

Methods: Methanol and water extracts of Datura metel leaves and flowers; Loranthus leaves and flowers; and Eucalyptus leaves were prepared and checked their UV absorption ability from $200 \mathrm{~nm}$ to $450 \mathrm{~nm}$. Different concentrations of the same extracts were tested for their sun protection factor (SPF) using Mansur formula from 290 to $320 \mathrm{~nm}$. All the extracts showed absorption at UV range.

Result: The calculated values of SPF were fallen in the range of 0.4-23.5. Among the three plants used in this study, methanol extract of Eucalyptus showed highest UV absorption than the other two plants. In vitro studies of a few phenolics from various plants have been found to be mutagenic. This might be the result of pro-oxidant than antioxidant action of these compounds. Keeping in view of human use as SPFs, it is indispensable to investigate the toxic effects of the extracts.

Conclusion: The preliminary findings of this study reveal that the methanol extract of Eucalyptus has a high sun protection effect. This extract can be used as additives in other sunscreen formulations to enhance their SPF.

Keywords: Datura metel, Loranthus, Eucalyptus, Sun protection factor, Methanol, Ultraviolet absorption.

(C) 2018 The Authors. Published by Innovare Academic Sciences Pvt Ltd. This is an open access article under the CC BY license (http://creativecommons. org/licenses/by/4. 0/) DOI: http://dx.doi.org/10.22159/ajpcr.2018.v11i4.23671

\section{INTRODUCTION}

Exposure to sun rays may lead to skin damages includes sunburns, skin cancer, oxidative damage to skin cells, and photoaging. The electromagnetic spectrum is divided into three regions: UV A is found in the region between 320 and $400 \mathrm{~nm}$ and is the least powerful wavelength band of UV radiation. It is longwave, black light, and not absorbed by the ozone layer. UV A acts primarily to cause the melanin pigments in the skin to oxidize (darken) creating the cosmetic tan and has limited power to cause erythema. UV B is found in the region between 280 and $320 \mathrm{~nm}$. It comprises the wavelengths primarily associated with erythema (sunburn) is also necessary for the production of Vitamin D in the skin and is primarily responsible for stimulating increased melanin production. UV B wavelengths (at $305 \mathrm{~nm}$ ) have 1000 times more erythemal power than UV A wavelengths. It is medium wave, mostly absorbed by the ozone layer. UV C is found in the region between approximately 200 and $280 \mathrm{~nm}$ and is called germicidal UV and shortwave completely absorbed by the ozone layer and the atmosphere. Even a short overexposure to UV $\mathrm{C}$ is very harmful to the eyes and causes severe erythema (sunburn). UV C radiation is filtered by the atmosphere before reaching the earth. UV $B$ radiation is not completely filtered out by the ozone layer and is responsible for the damages due to sunburn. UV A radiation reaches the deeper layers of the epidermis and dermis and provokes the premature aging of the skin $[1,2]$.

Sun protection factor is the abbreviation of SPF. This is a laboratory measure. This helps in grading the probable ability of a sunscreen to block UV B radiation. It is not a number that can be directly translated into an estimate of protection or safe behavior.
Chemical sunscreens, which are available in the market, are incorporated into moisturizers, lotions, creams, and hair tonics. Continuous usage of these chemical sunscreens are not safe from protection and unavoidable from side effects. In contrast, natural substances of plant origin are considered as potential sunscreen resources as they absorb UV radiation [3].

Oxygen free radicals induce damage to deoxyribonucleic acid; tissue damage leads to various diseases. The major role of antioxidants is to neutralize the effects of free radicals through different ways and may prevent the body from various diseases. Synthetic antioxidants are dangerous to human health. The search for effective, non-toxic natural compounds with antioxidant activity has been intensified in recent years [4]. In nature, UV light induces the accumulation of flavonoids and other phenolic compounds in epidermal tissues of the plant [5]. Recent research focuses on the use of UV light absorbing flavonoids and phenolics as antioxidants in sunscreens to provide protection from light. This opens a new area of using natural antioxidants in preventing UV-mediated diseases. Indian herbs have prospective antioxidant properties and the selected plants for the present investigation are also high in antioxidant activity [6-8]. In spite of having much literature on antioxidant activity of the selected plants, no absolute data were available on SPF. The goal of the present study is to evaluate the SPF and antisolar activity of water and methanol extracts of D. metel (leaf and flower), Loranthus longiflorus (parasite on Pongamia pinnata) (leaf and flower), and Eucalyptus sp. (leaf).

\section{METHODS}

Plant material and extract preparation

D. metel leaves and flowers, L. longiflorus flowers and leaves, and Eucalyptus leaves were collected from Kolar region, Karnataka, India. 
The herbaria of the plants were made, identified, and authenticated by Madhava Shetty, Assistant Professor, Department of Botany, Sri Venkateswara University, Tirupati.

\section{Extraction}

After collection, the plant materials were washed twice with tap water and then with distilled water. The materials were chopped into small pieces with clean cutter, removed the moisture by blotting paper and shade dried for about $15 \mathrm{~d}$. The dried materials were ground to fine powder and stored in airtight container till further use.

\section{Hot water and methanol extraction}

The extraction was performed according to the method described in United Nations Industrial Development Organization and the International Centre for Science and High Technology, 2008 [9]. The crude dry powder (10 g) was boiled in $160 \mathrm{ml}$ water for a defined time; it is then cooled, strained, and filtered using Whatman No 1 filter paper. The extract was then kept for drying to evaporate the water content in it. The dried material was scraped and used for the study. About $10 \mathrm{~g}$ of dried fine powder was added to $100 \mathrm{ml}$ of methanol, kept on a rotary shaker for $24 \mathrm{~h}$. It was then filtered and centrifuged at $5000 \mathrm{~g}$ for $15 \mathrm{~min}$. The supernatant was collected and the solvent was evaporated completely. The left out material was collected and was stored at room temperature in airtight bottles for further studies.

\section{UV absorption capacity or antisolar activity}

The antisolar activity was performed by UV-visible spectrophotometry [10]. Preliminary analysis was performed with all the water and methanol extracts. About $1 \mathrm{mg} / \mathrm{mL}$ of the extract was made in respective solvents and spectrophotometric (PerkinElmer Lambda 35 UV-visible spectrophotometer) readings were taken from 200 to $450 \mathrm{~nm}$ with $50 \mathrm{~nm}$ variation. All the readings were repeated 4 times at each point.

\section{Determination of SPF}

The determination of SPF is performed according to the method described by More [11]. From the dried extract, $1 \mathrm{mg} / \mathrm{mL}$ stock solution was made and made different concentrations such as $50 \mu \mathrm{g} / \mathrm{ml}, 100 \mu \mathrm{g} / \mathrm{ml}$, and $150 \mu \mathrm{g} / \mathrm{ml}$ with the respective solvents. Spectrophotometric readings of these solutions were taken in wavelength ranging from 290 to 320 at $5 \mathrm{~nm}$ interval and the readings were noted down. All the readings were taken in quadruplicate at each point. Mansur equation was used to determine the SPF values of the formulations.

$$
\mathrm{SPF}=\mathrm{CF} \times \sum_{290}^{320} \mathrm{EE}(\lambda) \times \mathrm{I}(\lambda) \times \operatorname{Abs}(\lambda)
$$

Mansur et al. (1986) developed a very simple mathematical equation which is as follows:

In this equation, $\mathrm{CF}=10$ (correction factor), $\mathrm{EE}(\lambda)=$ erythemogenic effect of radiation at wavelength $\lambda$, I $(\lambda)=$ intensity of solar light at wavelength $\lambda$, and abs $(\lambda)=$ absorbance of wavelength $\lambda$ by a solution of the preparation. The obtained absorbance values were multiplied by the EE $(\lambda)$ values; their summation was taken and multiplied by the correction factor 10 .

\section{RESULTS AND DISCUSSIONS}

SPF assesses the quantitative effectiveness of sunscreen formulation. The effectiveness of any sunscreen compound that prevents sunburns and other skin diseases should have a wide range of absorbance between 209 and $400 \mathrm{~nm}$. Finding out in vitro SPF is a useful tool for in vivo SPF measurement [12]. Sunscreens house a variety of chemicals that have specific absorbance in some part of the UV spectrum. There are a very few chemical substances that have absorbing capacity over the full range of UV. An initial UV absorption study was carried out by reading the absorbance between 200 and 450 with $50 \mathrm{~nm}$ interval. The results obtained from this selected plant extracts have shown good UV absorption activity. The extracts of flowers and leaves of all the plants exhibited maximum absorbance at $200 \mathrm{~nm}$ and $250 \mathrm{~nm}$ and the minimum absorbance at $400 \mathrm{~nm}$ and $450 \mathrm{~nm}$ indicates that the extracts have the ability to absorb UV light (Table 1). Based on this result, the study is taken further to perform SPF analysis.

\section{Determination of SPF using Mansur equation}

UV absorption results gave us an insight into perform SPF. SPF of the extracts was checked by absorption spectroscopy using Mansur equation method.

SPF of the extracts was determined by taking different concentrations of the extracts at 290-320 at $5 \mathrm{~nm}$ interval. It was observed that an increase in absorption is a concentration dependent. The calculated values of SPF were fallen in the range of 0.4-23.5. The leaf extracts of Eucalyptus in both water and methanol extracts have showed highest SPF activity, i.e., 17.9 and 23.5 at $150 \mu \mathrm{g} / \mathrm{ml}$ concentration when compared to the remaining plant extracts. D. metel methanol extract also showed similar SPF activity as like Eucalyptus water extract, i.e., 17.5 at $150 \mu \mathrm{g} / \mathrm{ml}$. The least activity was noticed in Loranthus leaf methanol extract, i.e., 0.4 , and all the other concentrations of Loranthus are also having least SPF activity when compared with the other two plants. Among the three plants used in this study, methanol extract of Eucalyptus showed highest UV absorption than the other two plants. The SPF activity of the selected plants with their graphical representation is shown below (Table 2; Fig. 1).

The sunscreen lotion or cream makes a bulletproof vest, which stops the UV photons. The molecules present in these sunscreens absorb UV, scatter, and reflect UV. A sunscreen product must have sufficient quantities of these protective agents to provide a high-level protection. The published literature shows that there is a strong correlation between SPF and phenolic compounds [13]. In general, sunscreens house variety of chemicals that have specific absorbance in a few parts of the UV spectrum. Only a few chemical substances have absorbance over the full range of UV, which is needed for any product to consider as wide spectrum sunscreen. As plants house wide range of natural compounds with a full range of UV absorbing capability, the study sis further progressed toward this SPF formulation. In vitro studies of a few phenolics from various plants have been found to be mutagenic. This might be the result of pro-oxidant than antioxidant action of these compounds. Keeping in view of human use as SPFs, it is indispensable to investigate the toxic effects of the extracts.

Table 1: Initial screening of UV absorption of selected plant parts from $200 \mathrm{~nm}$ to $450 \mathrm{~nm}$ with $50 \mathrm{~nm}$ interval

\begin{tabular}{|c|c|c|c|c|c|c|c|c|c|c|}
\hline \multirow[t]{2}{*}{ UV (nm) } & \multicolumn{2}{|c|}{$D$ flower } & \multicolumn{2}{|c|}{$D$ leaf } & \multicolumn{2}{|c|}{$L$ flower } & \multicolumn{2}{|c|}{$L$ leaf } & \multicolumn{2}{|c|}{$E$ leaf } \\
\hline & $\mathbf{M}$ & $\mathbf{W}$ & M & $\mathbf{W}$ & M & $\mathbf{W}$ & M & $\mathbf{W}$ & M & $\mathbf{W}$ \\
\hline 200 & 5.4 & 5.2 & 0.43 & 2.7 & 7.5 & 8.9 & 2.8 & 8.7 & 7.8 & 7.5 \\
\hline 300 & 1.6 & 0.72 & 1.07 & 1.2 & 1.5 & 0.66 & 0.97 & 1.17 & 3.4 & 2.2 \\
\hline 350 & 0.96 & 0.5 & 0.68 & 0.87 & 1.7 & 0.4 & 0.44 & 0.73 & 1.07 & 1.83 \\
\hline 400 & 0.5 & 0.5 & 0.52 & 0.5 & 0.41 & 0.16 & 0.42 & 0.28 & 0.18 & 0.87 \\
\hline 450 & 0.11 & 0.2 & 0.13 & 0.44 & 0.04 & 0.1 & 0.13 & 0.18 & 0.13 & 0.31 \\
\hline
\end{tabular}

M: Methanol, W: Water, D: Datura, L: Loranthus, E: Eucalyptus. UV: Ultraviolet 
Table 2: SPF values of the selected plant extracts at different concentrations at UV absorption between $290 \mathrm{~nm}$ and $320 \mathrm{~nm}$ with 5nm difference based on Mansur equation

\begin{tabular}{|c|c|c|c|c|c|c|c|}
\hline \multirow[t]{3}{*}{$\mathbf{n m}$} & \multirow[t]{3}{*}{ EE*I (Normalized) } & \multicolumn{6}{|c|}{ D. metel (leaf) } \\
\hline & & \multicolumn{3}{|l|}{ water } & \multicolumn{3}{|l|}{ methanol } \\
\hline & & $50 \mu \mathrm{g} / \mathrm{mL}$ & $100 \mu \mathrm{g} / \mathrm{mL}$ & $150 \mu \mathrm{g} / \mathrm{mL}$ & $50 \mu \mathrm{g} / \mathrm{mL}$ & $100 \mu \mathrm{g} / \mathrm{mL}$ & $150 \mu \mathrm{g} / \mathrm{mL}$ \\
\hline 290 & 0.01 & 0.020 & 0.02 & 0.05 & 0.04 & 0.07 & 0.12 \\
\hline 295 & 0.08 & 0.12 & 0.11 & 0.27 & 0.23 & 0.40 & 0.62 \\
\hline 300 & 0.28 & 0.36 & 0.37 & 0.89 & 0.77 & 1.39 & 2.12 \\
\hline 305 & 0.32 & 0.39 & 0.40 & 0.97 & 0.86 & 1.54 & 2.38 \\
\hline 310 & 0.18 & 0.21 & 0.21 & 0.52 & 0.44 & 0.91 & 1.35 \\
\hline 315 & 0.08 & 0.09 & 0.09 & 0.22 & 0.22 & 0.40 & 0.61 \\
\hline 320 & 0.01 & 0.02 & 0.02 & 0.04 & 0.04 & 0.08 & 0.13 \\
\hline SPF & 1 & $3.21 \pm 1.85$ & $3.028 \pm 1.85$ & $7.16 \pm 1.85$ & $6.33 \pm 5.08$ & $6.70 \pm 5.08$ & $17.50 \pm 5.08$ \\
\hline \multirow[t]{3}{*}{$\mathbf{n m}$} & EE*I (Normalized) & \multicolumn{6}{|c|}{ D. metel (flower) } \\
\hline & & \multicolumn{3}{|l|}{ water } & \multicolumn{3}{|l|}{ methanol } \\
\hline & & $50 \mu \mathrm{g} / \mathrm{mL}$ & $100 \mu \mathrm{g} / \mathrm{mL}$ & $150 \mu \mathrm{g} / \mathrm{mL}$ & $50 \mu \mathrm{g} / \mathrm{mL}$ & $100 \mu \mathrm{g} / \mathrm{mL}$ & $150 \mu \mathrm{g} / \mathrm{mL}$ \\
\hline 290 & 0.01 & 0.01 & 0.01 & 0.03 & 0.02 & 0.04 & 0.00 \\
\hline 295 & 0.08 & 0.07 & 0.13 & 0.20 & 0.09 & 0.20 & 0.30 \\
\hline 300 & 0.28 & 0.31 & 0.54 & 0.73 & 0.31 & 0.65 & 0.96 \\
\hline 305 & 0.32 & 0.35 & 0.60 & 0.82 & 0.36 & 0.72 & 1.05 \\
\hline 310 & 0.18 & 0.20 & 0.33 & 0.45 & 0.19 & 0.40 & 0.60 \\
\hline 315 & 0.08 & 0.08 & 0.15 & 0.19 & 0.08 & 0.18 & 0.27 \\
\hline 320 & 0.01 & 0.01 & 0.03 & 0.04 & 0.01 & 0.00 & 0.05 \\
\hline SPF & 1 & $6.37 \pm 0.59$ & $4.42 \pm 0.59$ & $5.99 \pm 0.59$ & $4.64 \pm 1.54$ & $5.3 \pm 1.54$ & $7.83 \pm 1.54$ \\
\hline \multirow[t]{3}{*}{$\mathbf{n m}$} & EE*I (Normalized) & \multicolumn{6}{|c|}{ L. longiflorus (flower) } \\
\hline & & \multicolumn{3}{|l|}{ water } & \multicolumn{3}{|l|}{ methanol } \\
\hline & & $50 \mu \mathrm{g} / \mathrm{mL}$ & $100 \mu \mathrm{g} / \mathrm{mL}$ & $150 \mu \mathrm{g} / \mathrm{mL}$ & $50 \mu \mathrm{g} / \mathrm{mL}$ & $100 \mu \mathrm{g} / \mathrm{mL}$ & $150 \mu \mathrm{g} / \mathrm{mL}$ \\
\hline 290 & 0.01 & 0.00 & 0.01 & 0.02 & 0.00 & 0.01 & 0.01 \\
\hline 295 & 0.08 & 0.07 & 0.11 & 0.15 & 0.04 & 0.09 & 0.18 \\
\hline 300 & 0.28 & 0.32 & 0.43 & 0.59 & 0.17 & 0.33 & 0.41 \\
\hline 305 & 0.32 & 0.37 & 0.49 & 0.65 & 0.19 & 0.37 & 0.47 \\
\hline 310 & 0.18 & 0.21 & 0.26 & 0.35 & 0.10 & 0.20 & 0.26 \\
\hline 315 & 0.08 & 0.09 & 0.11 & 0.15 & 0.04 & 0.09 & 0.12 \\
\hline 320 & 0.01 & 0.01 & 0.01 & 0.03 & 0.01 & 0.02 & 0.02 \\
\hline SPF & 1 & $2.7 \pm 0.64$ & $3.5 \pm 0.64$ & $4.8 \pm 0.64$ & $1.4 \pm 0.58$ & $2.7 \pm 0.58$ & $3.4 \pm 0.58$ \\
\hline \multirow[t]{3}{*}{ nm } & EE*I (Normalized) & \multicolumn{6}{|c|}{ L. longiflorus (flower) } \\
\hline & & \multicolumn{3}{|l|}{ Water } & \multicolumn{3}{|l|}{ methanol } \\
\hline & & $50 \mu \mathrm{g} / \mathrm{mL}$ & $100 \mu \mathrm{g} / \mathrm{mL}$ & $150 \mu \mathrm{g} / \mathrm{mL}$ & $50 \mu \mathrm{g} / \mathrm{mL}$ & $100 \mu \mathrm{g} / \mathrm{mL}$ & $150 \mu \mathrm{g} / \mathrm{mL}$ \\
\hline 290 & 0.01 & 0.01 & 0.03 & 0.05 & 0.00 & 0.01 & 0.01 \\
\hline 295 & 0.08 & 0.10 & 0.18 & 0.31 & 0.02 & 0.05 & 0.05 \\
\hline 300 & 0.28 & 0.41 & 0.66 & 1.12 & 0.05 & 0.16 & 0.15 \\
\hline 305 & 0.32 & 0.47 & 0.73 & 1.25 & 0.06 & 0.17 & 0.16 \\
\hline 310 & 0.18 & 0.26 & 0.39 & 0.69 & 0.03 & 0.09 & 0.08 \\
\hline 315 & 0.08 & 0.11 & 0.17 & 0.30 & 0.01 & 0.04 & 0.03 \\
\hline 320 & 0.01 & 0.02 & 0.03 & 0.06 & 0.00 & 0.00 & 0.00 \\
\hline SPF & 1 & $3.4 \pm 2.29$ & $5.3 \pm 2.29$ & $9.1 \pm 2.29$ & $0.4 \pm 0.17$ & $1.3 \pm 0.17$ & $1.2 \pm 0.17$ \\
\hline \multirow[t]{3}{*}{$\mathbf{n m}$} & EE*I (Normalized) & Eucalyptus & & & & & \\
\hline & & water & & & methanol & & \\
\hline & & $50 \mu \mathrm{g} / \mathrm{mL}$ & $100 \mu \mathrm{g} / \mathrm{mL}$ & $150 \mu \mathrm{g} / \mathrm{mL}$ & $50 \mu \mathrm{g} / \mathrm{mL}$ & $100 \mu \mathrm{g} / \mathrm{mL}$ & $150 \mu \mathrm{g} / \mathrm{mL}$ \\
\hline 290 & 0.01 & 0.03 & 0.07 & 0.09 & 0.02 & 0.04 & 0.11 \\
\hline 295 & 0.08 & 0.23 & 0.51 & 0.75 & 0.22 & 0.44 & 0.72 \\
\hline 300 & 0.28 & 0.75 & 1.67 & 2.46 & 0.78 & 1.61 & 2.44 \\
\hline 305 & 0.32 & 0.73 & 1.64 & 2.39 & 0.82 & 1.71 & 2.58 \\
\hline 310 & 0.18 & 0.34 & 0.77 & 1.11 & 0.43 & 0.90 & 1.36 \\
\hline 315 & 0.08 & 0.13 & 0.29 & 0.42 & 0.18 & 0.38 & 5.76 \\
\hline 320 & 0.01 & 0.02 & 0.05 & 0.07 & 0.03 & 0.06 & 0.11 \\
\hline SPF & 1 & $5.5 \pm 4.3$ & $12.3 \pm 4.3$ & $17.9 \pm 4.3$ & $6.1 \pm 9.58$ & $12.6 \pm 9.58$ & $23.5 \pm 9.58$ \\
\hline
\end{tabular}

mean \pm SD, $n=4$. SPF: Sun protection factor, L. longiflorus: Loranthus longiflorus, D. metel: Datura metel

All the three plants have phenolic compounds and our present study has shown the extracts absorbed UV radiation [14]. UV radiation is highly genotoxic and this is the first stage of skin cancer. To protect from UV radiation, antimutagens having the potentials against UV are to be considered, in particular from plant source. The SPF is the quantitative measurement of the effectiveness of any sunscreen formulation. It is effective in treating sunburn and various skin damage conditions [15]. Although there is availability of various synthetic sunscreens, their 


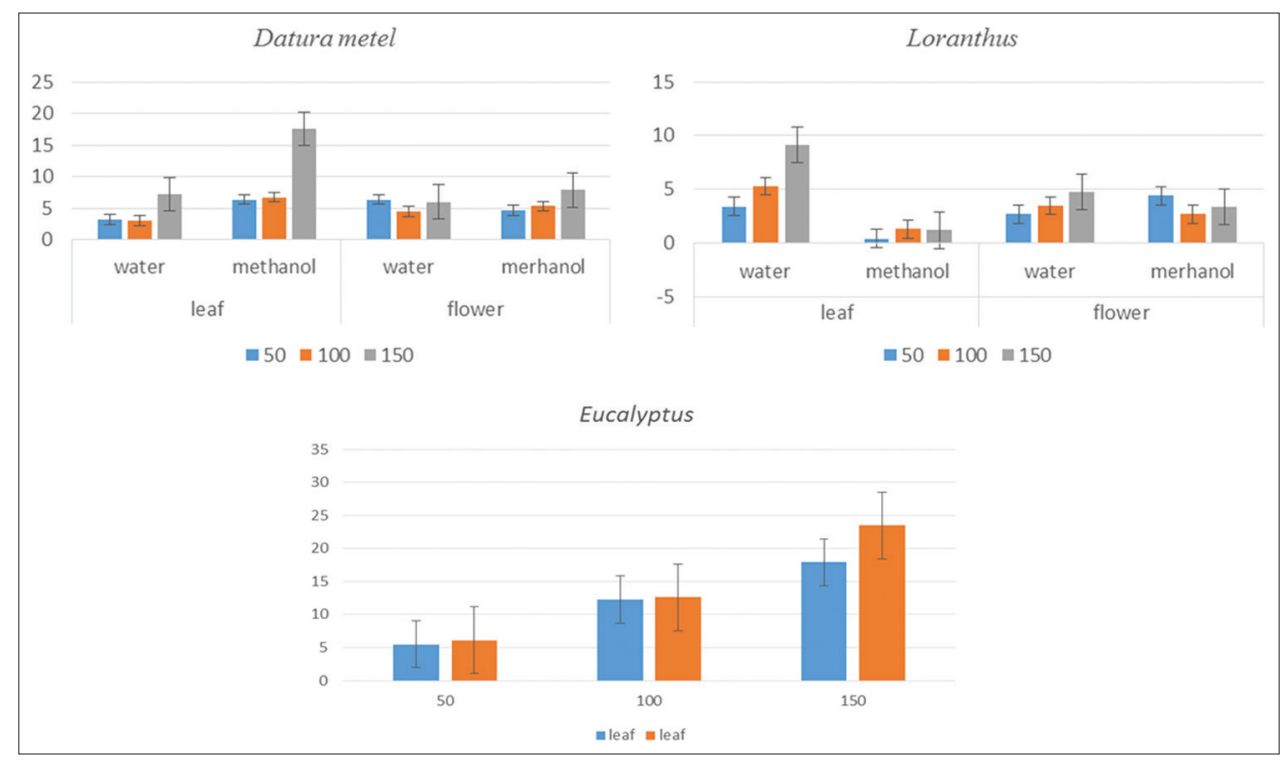

Fig.1: Graphical representation of SPF activity of D. metel, Loranthus and Eucalyptus at different concentrations

application is limited because of their harmful effects on the skin. Consumer acceptance is more when the sunscreens are prepared with plant extracts. Apart from filtering UV radiation, herbal combinations have several beneficial effects to the skin [16]. A study conducted by Silva and his coworkers showed the SPF activity of the crude extract of Pothomorphe umbellate root and found that the SPF value to be 21.53 which is similar to the result obtained from our study [17]. Another study states that due to the presence of high amounts of flavonoids and phenolics there is an increase in the SPF value in the plant extracts such as D. moldavica and V. tricolor with SPF activity of 24.79 and 25.69 [18]. Another study conducted by Mishra and his coworkers has stated that flavonoids and phenolics have excellent antioxidant and photoprotective properties [19]. Therefore, it is necessary to screen for the phenolics and flavonoids of the selected plant species to prepare topical sunscreen formulations from these extracts.

Recentresearch focuses on the use of antioxidants in sunscreens to provide photoprotection. Plants with antioxidants are the new possible source for the treatment and prevention of UV-mediated allergies, tan, etc. $D$. metel plant contains phenolic and flavonoids with free radical scavenging activity, which correlates the antioxidant property [20]. Experiments on Loranthus begwensis showed the presence of phenolic compounds and these compounds have to be reported to have antioxidant properties. Since Loranthus is a parasite, the presence and percentage of metabolites vary from plant to plant based on its host plant [21]. Phytochemical screening of the plants showed the presence of flavonoids, terpenoids, saponins, and reducing sugars. In addition to other antioxidant constituents, Eucalyptus has essential oils in leaves which make the extract to absorb more UV light than the other two plants studied [22].

\section{CONCLUSIONS}

The preliminary findings of this study reveal that the methanol extract of Eucalyptus has a high sun protection effect. This extract can be used as additives in other sunscreen formulations to enhance their SPF. A good correlation might exist between the phenolic components of the selected plants and the SPF activity, according to the obtained literature and this would offer an exciting avenue for further research toward the development of herbal cosmetics.

\section{ACKNOWLEDGMENT}

Authors of the present study are grateful to the Department of Cell Biology and Molecular Genetics, Sri Devaraj Urs Academy of Higher Education and Research, for providing the facilities to carry out the work.

\section{AUTHORS CONTRIBUTIONS}

The corresponding author (Dr. Kiranmayee P.) is the principal investigator of the present work, who reviewed the article. The first author collected the plant material, made the extracts. The second author performed the experiment, helped in manuscript writing; the third author helped in performing the experiment, the fourth author monitored the overall performance of the project.

\section{CONFLICT OF INTERESTS}

The authors declare that no competing interest exists.

\section{REFERENCES}

1. Dutra EA, Oliveira DA, Kedor-Hackmann ER, Santoro MI. Determination of sun protection factor (SPF) of sunscreens by ultraviolet spectrophotometry. Braz J Pharm Sci 2004;40:381-5.

2. Kale S, Sonawane A, Ansari A, Ghoge P, Waje A. Formulation and in vitro determination of sun protection factor of Ocimum basilicum, Linn. leaf oils sunscreen cream. Int J Pharma Pharma Sci 2010;2:147-9.

3. Thompson SC, Jolley D, Marks R. Reduction of solar keratoses by regular sunscreen use. N Engl J Med 1993;329:1147-51.

4. Gupta VK, Sharma SK. Plants as natural antioxidants. Nat Prod Radiance 2006;5:326-34.

5. Strack D. Phenolic metabolism. In: Dey PM, Harborne JB, editors. Plant Biochemistry. London: Academic Press; 1997. p. 388-92.

6. El-Ghorab AH, El-Massry KF, Marx F, Fadel HM. Antioxidant activity of Egyptian Eucalyptus camaldulensis var. Brevirostris leaf extracts. Nahrung 2003;47:41-5.

7. Sangeetha S, Deepa M, Sugitha N, Mythili S, Sathiavelu A. Antioxidant activity and phytochemical analysis of Datura metel. Int J Drug Dev Res 2014;6:280-5.

8. Chandrakasan L, Neelamegam R. In vitro studies on antioxidants and free radical scavenging activities in the extracts of Loranthus longiflorus Desr. Bark samples obtained from two host trees. J Phytol 2011;3:22-30

9. Handa SS, Khanuja SP, Longo G, Rakesh DD. Extraction Technologies for Medicinal and Aromatic Plants. Trieste: United Nations Industrial Development Organization and The International Centre for Science and High Technology, 2008.

10. Vinayak VP, Patil SB, Kondawar MS, Naikwade NS, Magdum CS. Study of methanolic extract of flower of Spathodea campanulata L. As an anti-solar. Int J Green Pharm 2008;3:248-9.

11. More BH, Sakharwade SN, Tembhurne SV, Sakarkar DM. Evaluation of sunscreen activity of cream containing leaves extract of Butea monosperma for topical application. Int J Cosmet Sci 2013;3:1-6.

12. Kaur CD, Saraf S. In vitro sun protection factor determination of herbal 
oils used in cosmetics. Pharm Res 2010;2:22-5.

13. Yasmeen S, Gupta P. In vitro demonstration of Dalbergia sissoo (Indian rosewood) methanolic extracts as potential agents for sun screening and Dan nick prevention. Int J Pharm Pharm Sci 2016;8:175-81.

14. Ebrahimzadeh MA, Enayatifard R, Khalili M, Ghaffarloo M, Saeedi M, Yazdani Charati J, et al. Correlation between sun protection factor and antioxidant activity, phenol and flavonoid contents of some medicinal plants. Iran J Pharm Res 2014;13:1041-7.

15. Svobodová A, Psotová J, Walterová D. Natural phenolic in the prevention of UV-induced skin damage, a review. Biomed Pap Med Fac Univ Palacky Olomouc Czech Repub 2003;147:137-45

16. Mbanga L, Mpiana PT, Mbala M, Ilinga L, Ngoy B, Mvingu K, et al. Comparative in vitro sun protection factor (SPF) values of some herbal extracts found in Kinshasa by Ultraviolet Spectrophotometry. J Phy Chem Sci 2015;2:1-6.

17. Silva VV, Ropke CD, Almeida RL, Miranda DV, Kera CZ, Rivelli DP, et al, Chemical stability and SPF determination of Pothomorphe umbellata extract gel and photostability of 4-nerolidylcathecol. Int J Pharm 2005;303:125-31.

18. Khazaeli P, Mehrabani M. Screening of sun protective activity of the ethyl acetate extracts of some medicinal plants. Iran J Pharm Res 2008;7:5-9.

19. Mishra A, Mishra A, Chattopadhyay P. Assessment of in vitro sun protection factor of Calendula officinalis L. (Asteraceae) essential oil formulation. J Young Pharm 2012;4:17-21

20. Roy S, Pawar S, Chowdhary A. Evaluation of in vitro cytotoxic and antioxidant activity of Datura metel Linn. and Cynodon dactylon Linn. Extracts. Pharmacognosy Res 2016;8:123-7.

21. Oboh G, Babatola LJ, Ademiluyi AO. Antioxidant properties of phenolic extracts of African Mistletoes (Loranthusbegwensis L.) from Kolanut and Breadfruit trees. Food Sci Qual Manage 2014;32:6-11.

22. Miguel MG. Antioxidant and anti-inflammatory activities of essential oils: A short review. Molecules 2010;15:9252-87. 